\title{
Tracing infiltration and recharge using stable isotope in Taihang Mt., North China
}

Fadong Li $\cdot$ Xianfang Song $\cdot$ Changyuan Tang ·

Changming Liu $\cdot$ Jingjie Yu $\cdot$ Wanjun Zhang

Published online: 8 May 2007

(C) Springer-Verlag 2007

\section{Erratum to: Environ Geol}

\section{DOI 10.1007/s00254-007-0683-0}

Unfortunately, an error occurred in Fig. 9. The correct figure is given below:

The online version of the original article can be found at http://dx.doi.org/10.1007/s00254-007-0683-0.

\section{F. Li $(\bowtie)$}

Graduate School of Science and Technology,

Chiba University,

Chiba 263-8522, Japan

e-mail: lifadong@gmail.com; lifadong@graduate.chiba-u.jp

\section{F. Li · C. Liu $\cdot$ W. Zhang}

Center for Agricultural Resources Research,

Institute of Genetics and Developmental Biology,

Chinese Academy of Sciences,

Shijiazhuang 050021, People's Republic of China

X. Song · C. Liu $\cdot$ J. Yu

Key Laboratory of Water Cycle and Related Land Surface Processes, Institute of Geographical Sciences and Natural Resources Research,

Chinese Academy of Science,

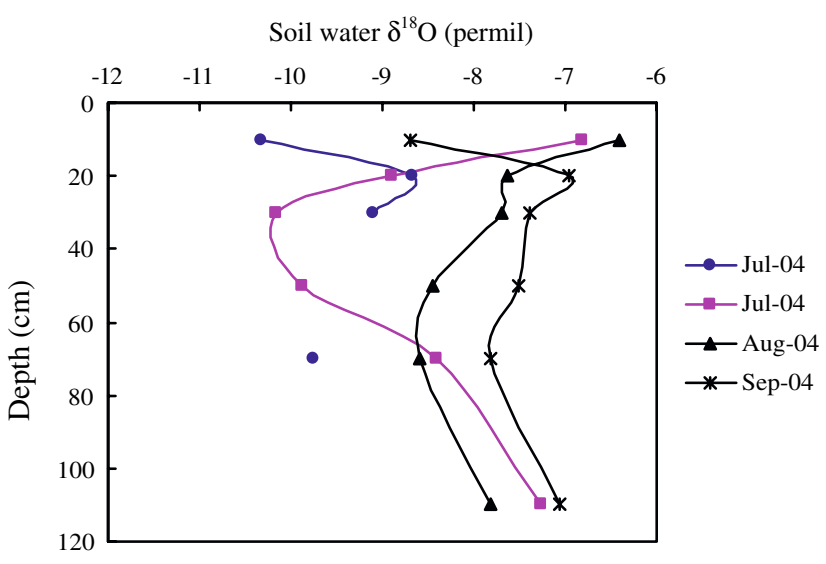

Beijing 100101, People's Republic of China

C. Tang

Faculty of Horticulture,

Chiba University,

Chiba 271-8510, Japan

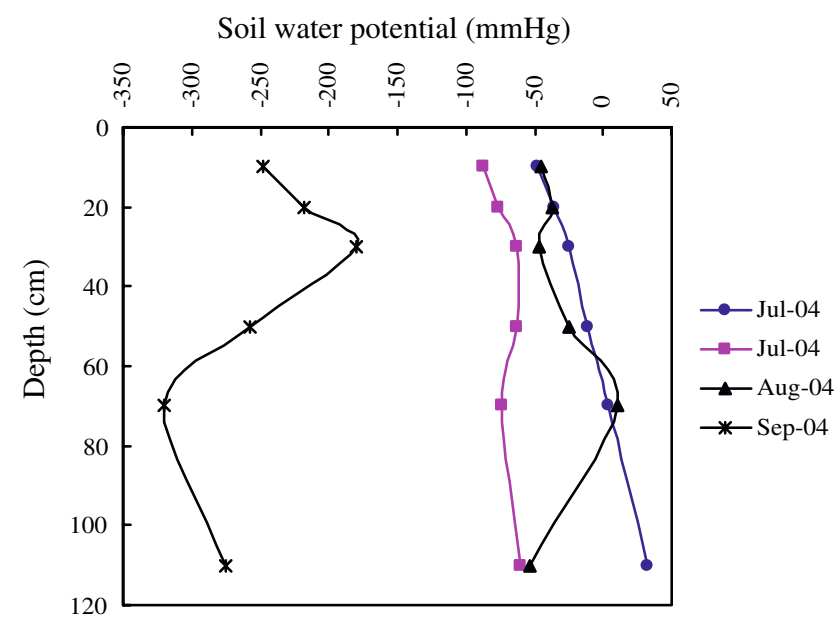

Fig. 9 Soil water $\delta^{18} \mathrm{O}$ and potential profiles at Site A in 2004 